Ciência Florestal, Santa Maria, v. 27, n. 2, p. 549-556, abr.-jun., 2017

ISSN 1980-5098

\title{
AVALIAÇÃO DO USO SUSTENTÁVEL DA ARBORIZAÇÃO URBANA NO MUNICÍPIO DE CAFEARA, PARANÁ
}

\author{
EVALUATION OF SUSTAINABLE USE OF URBAN AFFORESTATION IN CAFEARA CITY, \\ PARANÁ STATE
}

\author{
João Karlos Locastro ${ }^{1}$ José Luiz Miotto ${ }^{2}$ Bruno Luiz Domingos De Angelis ${ }^{3}$ \\ Marcelo Galeazzi Caxambu ${ }^{4}$
}

\begin{abstract}
RESUMO
O devido estudo tem por finalidade avaliar condições de sustentabilidade da arborização presente no acompanhamento viário de Cafeara - PR, além de recomendar possíveis técnicas de manejo aplicáveis à vegetação no meio urbano. Para tanto, realizou-se a elaboração de um inventário arbóreo associado à prática de entrevistas in loco, possibilitando o diagnóstico de espécies existentes na área de estudo e a verificação do comportamento da arborização. Com a elaboração da pesquisa, constatou-se que o município apresentou desenvolvimento de vegetação sustentável, comprovado pelo plantio de mudas nativas, elaboração de projetos ambientais e mantenimento de técnicas de manejo. Apesar do reconhecimento de técnicas sustentáveis executadas junto à arborização, foi possível verificar que a municipalidade em questão dispõe de potencial para avanços ainda significativos quanto ao tema proposto, reduzindo assim, parte dos conflitos arbóreos com equipamentos públicos e potencializando os benefícios da vegetação. Como alternativa para solução dos problemas existentes recomendou-se o estímulo de medidas corretivas, dentre elas: plantio de espécies arbóreas em locais de intensa insolação, disposição de resíduos da poda como forma de adubo, cultivo de espécies com potencial florístico e/ou frutífero, além da elaboração de um plano municipal de manejo para a arborização. Por todo exposto, notou-se que, embora haja necessidade de readequações, o sistema de arborização tem sido eficiente quanto a sua funcionalidade, atuando de forma sustentável em virtude da execução de ações de gestão pública e participação cidadã.
\end{abstract}

Palavras-chave: inventário arbóreo; manejo; projetos ambientais.

\section{ABSTRACT}

The proper study aims to assess sustainability conditions of afforestation in Cafeara streets, PR state, and recommend possible management techniques for vegetation in urban areas. Therefore, there was the development of a tree inventory associated with the practice of on-site interviews, allowing the diagnosis of species in the study area and verify the behavior of afforestation. Along with the preparation of the research, it was found that the city had development of sustainable vegetation, evidenced by planting native seedlings, preparation of environmental projects and maintenance management techniques. Despite the recognition of sustainable techniques performed by the trees, we observed that the studied municipality has the potential for significant progress on the proposed theme, thus reducing part of arboreal conflicts with public facilities and enhancing the benefits of vegetation. As an alternative for the resolution of the existing problems, it is recommended the stimulation of corrective measures, among them: planting tree species in

1 Engenheiro Ambiental, Mestrando em Engenharia Urbana, Departamento de Engenharia Civil, Centro de Tecnologia, Universidade Estadual de Maringá, Av. Colombo, 5.790, Zona 07, CEP 87020-900, Maringá (PR), Brasil. jklocastro@gmail.com

2 Engenheiro Civil, Dr., Professor Adjunto do Departamento de Engenharia Civil, Universidade Estadual de Maringá, Av. Colombo, 5.790, Zona 07, CEP 87020-900, Maringá (PR), Brasil. jlmiotto@uem.br

3 Agrônomo, Dr., Professor Associado ao Departamento de Agronomia, Universidade Estadual de Maringá, Av. Colombo, 5.790, Zona 07, CEP 87020-900, Maringá (PR), Brasil. brucagen@uol.com.br

4 Engenheiro Florestal, Dr., Professor Adjunto do Departamento de Engenharia Ambiental, Universidade Tecnológica Federal do Paraná, BR 369 km 0,5, CEP 87301-006, Campo Mourão (PR), Brasil. mcaxambu@utfpr.edu.br

Recebido para publicação em 11/03/2015 e aceito em 19/08/2015 
places of intense sunstroke, waste disposal pruning as a form of fertilizer, crop species with floristic and/ or fruitful potential, besides the development of a municipal management plan for afforestation. For all the above, it was noted that although there is need for readjustments, the afforestation system has been effective as its functionality, acting sustainably due to the implementation of public management actions and citizen participation.

Keywords: inventory tree; management; environmental projects.

\section{INTRODUÇÃO}

Com o desenvolvimento do mundo moderno, avanço de sistemas econômicos e financeiros, tornase cada vez mais comum o surgimento de centros urbanos que, de forma geral, modificam a paisagem local e alteram o equilíbrio natural existente.

De acordo com Cerqueira e Silva (2013), esse crescimento das cidades tem provocado a substituição das árvores no ambiente por elementos conhecidos como a pavimentação e as construções, resultando, deste modo, em uma série de problemas, tais como: impermeabilização do solo, aumento da temperatura local, diminuição da biodiversidade e elevação de danos à saúde.

Como forma de minimizar os problemas obtidos e aproximar o homem da natureza, a partir do século XVII, a arborização passou a fazer parte dos espaços públicos e foi introduzida nas cidades com o objetivo estético cultural (GOUVÊA, 2001).

A cidade do Rio de Janeiro, por exemplo, foi o primeiro município brasileiro a implantar um projeto de arborização, tendo o cultivo de Palmeiras Imperial como forma de embelezar os jardins da então família Real (ELETRICIDADE DE SÃO PAULO, 1995). Consoante à prática de arborização que se espalhou por todo Rio de Janeiro, outros estados e cidades a exemplo deste, passaram a arborizar praças e avenidas, incentivando o surgimento de municípios com áreas de arborização consolidada.

Algumas cidades como Maringá e Curitiba tornaram-se, ao longo dos anos, referência quanto à arborização urbana nacional (MILANO; DALCIN, 2000). Recentemente, pequenos municípios também demonstraram preocupação quanto ao tema e cidades como Cafeara no Paraná, passaram a desenvolver projetos urbanísticos voltados para uma arborização mais sustentável, focada no ambiente e na população que o cerca.

A realidade é que apesar de a arborização estar difundida em tantos municípios brasileiros e ser destaque em várias municipalidades ainda há uma carência de projetos de arborização mais incipientes e que realmente forneçam benefícios advindos da arborização como: melhoria da qualidade do ar, sombreamento, estabilidade microclimática, atenuação de ruídos, além de alimentação e abrigo de animais (MELLO FILHO, 1985).

Como um todo, verifica-se que a vegetação empregada no contexto urbano, além dos benefícios já citados, desempenha um papel indispensável para os homens com atuação direta sob seu bem-estar físico e psíquico (BALENSIEFER; WIECHETECK, 1985), sendo o elo urbano entre os seres humanos e a natureza.

Entretanto, para a continuidade dos benefícios propostos é necessária uma transição da atual situação das cidades para um futuro sustentável no qual o manejo das áreas verdes deverá contemplar o bem-estar ambiental, social e econômico das sociedades urbanas (LAERA, 2005).

A fim de promover o verde urbano de forma mais sustentável, é necessário atentar-se à obtenção de um maior conhecimento sobre as condições da arborização. De acordo com Milano (1988), a prática de inventários arbóreos auxilia neste propósito e pode ser uma alternativa eficiente para caracterizar a vegetação.

Estes estudos como um todo contribuem para o entendimento do espaço e proporcionam a identificação de fatores como: origem das espécies arbóreas, sua distribuição no perímetro urbano, além condições de manejo. Ressalta-se ainda a facilidade de emprego do método proposto, podendo ser executados desde municípios pequenos como Cafeara - PR, até municípios mais populosos, tendo exemplo a cidade de Curitiba - PR.

Neste contexto, o presente estudo visa realizar um levantamento quali-quantitativo da arborização viária urbana do município de Cafeara - PR, para verificar condições de sustentabilidade da arborização existente e recomendar possíveis técnicas de manejo da vegetação aplicáveis no meio urbano do município 
proposto.

\section{MATERIAL E MÉTODOS}

O trabalho foi realizado no município de Cafeara-PR (Figura 1) e versou na realização de inventário arbóreo, além de um levantamento bibliográfico a respeito de práticas desenvolvidas em localidades que se preocupam com a questão do verde urbano.
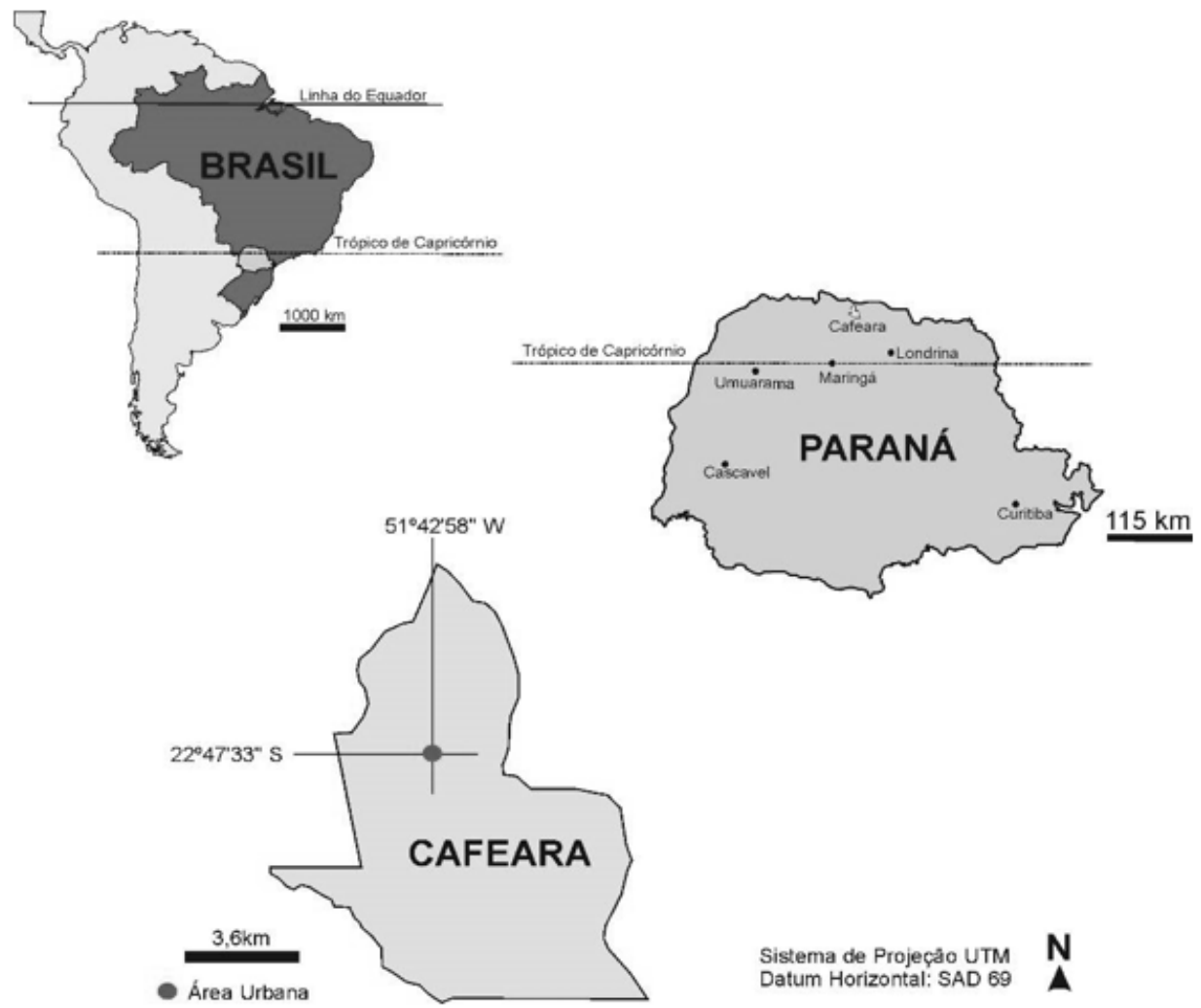

Sistema de Projeçấo UTM Datum Horizontal: SAD 69

\section{N}

Fonte: Adaptado de INSTITUTO DE TERRAS, CARTOGRAFIA E GEOCIÊNCIAS (2014).

FIGURA 1: Mapa de localização da área de estudo.

FIGURE 1: Location map of the study area.

Para elaboração do inventário foi realizada campanhas in loco com o intuito de coletar dados referentes a cada espécie arbórea existente, para posterior identificação do material botânico.

Durante exercício da pesquisa foram anotadas em fichas de campo características pertinentes aos indivíduos encontrados, como: hábitos da planta, aspectos físicos e possíveis interferências com equipamentos públicos. O procedimento de coleta e herborização seguiu a metodologia proposta por Fidalgo e Bononi (1989).

Após coleta de dados, as espécies registradas foram observadas e identificadas por meio de comparação com chave dicotômica e literatura, ou por auxílio de um profissional com habilidades na área. As plantas seguiram a classificação de famílias botânicas proposta em APG III (ANGIOSPERM PHYLOGENY GROUP, 2009) e os epítetos específicos, a Lista da Flora do Brasil (JARDIM BOTÂNICO DO RIO DE JANEIRO, 2013) e INTERNATIONAL PLANT NAMES INDEX (2013).

Para determinação das condições de manejo arbóreo foram realizadas entrevistas com moradores locais, colaboradores responsáveis pelo viveiro municipal e com representantes da própria administração pública.

Utilizaram-se ainda registros fotográficos como forma de retratar a morfologia vegetal e identificar técnicas de manejo geralmente aplicadas à vegetação, dentre elas: podas, mudas recém-plantadas e necessidade de remoção de tocos. 


\section{RESULTADOS E DISCUSSÃO}

Consoante ao inventário realizado na cidade de Cafeara - PR verificou-se que o município apresenta 1.885 espécimes arbóreos, sendo estes distribuídos em 30 famílias botânicas e 51 diferentes espécies (Tabela 1).

Dos indivíduos arbóreos encontrados, constatou-se a predominância de três espécies principais, dentre elas: Ficus benjamina L. (26,7\%), Licania tomentosa (Benth.) Fritsch (14,2\%) e Pachira aquatica Aublet (12,0\%) (Tabela 1). Alguns autores como Biondi e Althus (2005) alertam para o risco da dominância de poucas espécies em um determinado local, pois, segundo os mesmos, o presente fato facilita a propagação de pragas e doenças e pode ser um problema futuro para os ambientes urbanos, inclusive para Cafeara.

Em análise aos espécimes arbóreos encontrados em vias públicas do município, percebe-se o predomínio de exemplares nativos, sendo estes $52,4 \%$ de todos os indivíduos registrados na cidade. Em outros municípios brasileiros como Chapadão do Sul - MS verifica-se situação inversa, com o predomínio de indivíduos arbóreos exóticos (PELEGRIM et al., 2012). A maior ocorrência de plantas exóticas em relação às nativas pode ser apontada como um problema, visto que indivíduos exóticos nem sempre se adaptam às novas condições em que foram plantados (DANTAS; SOUZA, 2004) e, por vezes, não apresentam interação com a fauna, impossibilitando assim a realização de um dos maiores benefícios da vegetação ao meio urbano.

Outro aspecto analisado no município foi a ocorrência de danos aos patrimônios particulares e públicos em virtude da má-disposição dos indivíduos arbóreos, o que de certa forma contraria o conceito de arborização sustentável, com a ampliação de gastos em decorrência da manutenção das árvores no meio urbano. A realidade é que falta planejamento quanto às espécies a serem plantadas e com isto, tornam-se comuns situações como: soerguimento de calçadas, danos à fiação ou presença de tocos que atrapalham a movimentação de transeuntes (Figura 2).

Neste estudo, por exemplo, verificou-se que a espécie Ficus benjamina L. apresentou sérios problemas quanto ao calçamento, sendo a espécie mais conflituosa com equipamentos públicos na área de estudo. Como forma de desenvolvimento de uma arborização mais sustentável no município recomenda-se a elaboração de projetos de supressão desta espécie, iniciando-se pela retirada de espécimes inseridos em locais com calçamento e sob fiação.

Outro ponto de interesse verificado quanto ao assunto foi a presença de tocos encontrados em locais de passeio. Na cidade em questão, foi possível a constatação de 11 tocos que atrapalham a movimentação de pedestres e servem, por vezes, como depósito de resíduos. A questão relacionada aos tocos foi apontada pelos moradores locais como um dos maiores problemas da arborização, tendo responsabilidade compartilhada entre órgãos públicos e proprietários de imóveis.

Apesar dos questionamentos citados acima, a arborização estudada apresentou nos últimos anos certo avanço em relação ao tema. De acordo com representantes da gestão pública, a municipalidade vem se preocupando com questões de manejo da vegetação, comprovado pela intensificação do plantio de espécies nativas, mantenimento constante das podas e uso da vegetação como forma de atrair predadores naturais do Aedes aegypt (Linnaeus) (Figura 3 ).

Quando indagados a respeito das árvores presentes no município, os moradores ressaltaram que, por meio do manejo realizado, a arborização se tornou referência para a cidade, destacando-a em toda região. Algumas pessoas, por exemplo, relataram que o cuidado com a poda e com canteiros centrais vai além do embelezamento natural e transmite qualidade de vida aos moradores.

Os responsáveis pelo viveiro municipal mencionaram durante a entrevista que o município tem adotado o plantio de duas espécies nativas recentemente, sendo elas: Licania tomentosa (Benth.) Fritsch e Tibouchina granulosa (Ders.) Cogn. Segundo os mesmos, esta pequena ação reflete em melhorias para o ambiente, pois valoriza a flora nativa.

Entre as técnicas incentivadas pelo município quanto à arborização destacou-se o surgimento de projetos em parceria com escolas municipais, incentivando o plantio de mudas da espécie Crotalaria juncea L. Para a Secretaria Municipal de Meio Ambiente, esta espécie tem a finalidade de atrair insetos da ordem Odonata (libélulas) que auxiliam no combate $a ̀$ dengue.

O município conta ainda com o desenvolvimento de projetos do estado para formação de técnicos 
TABELA 1: Levantamento da arborização viária urbana do município de Cafeara - Paraná.

TABLE 1: Survey of afforestation street in Cafeara city - Paraná state.

\begin{tabular}{|c|c|c|c|}
\hline Família & Espécie & IND & $\mathrm{P}$ \\
\hline \multirow{3}{*}{ Anacardiaceae } & Mangifera indica $\mathrm{L}$. & 29 & $\mathrm{E}$ \\
\hline & Schinus molle L. & $\begin{array}{l}29 \\
25\end{array}$ & $\mathrm{~N}$ \\
\hline & Schinus terebinthifolius Raddi. & $\begin{array}{c}25 \\
5\end{array}$ & $\mathrm{~N}$ \\
\hline \multirow[t]{2}{*}{ Annonaceae } & Annona squamosa $\mathrm{L}$. & $\begin{array}{l}5 \\
2\end{array}$ & $\mathrm{E}$ \\
\hline & Nerium oleander L. & $\begin{array}{c}2 \\
14\end{array}$ & $\mathrm{E}$ \\
\hline \multirow{3}{*}{ Apocynaceae } & Tabernaemontana catharinensis A. DC. & $\begin{array}{c}14 \\
4\end{array}$ & $\mathrm{~N}$ \\
\hline & Plumeria rubra $\mathrm{L}$. & 4 & $\mathrm{~N}$ \\
\hline & Thevetia thevetioides (Kunth) K.Schum & $\begin{array}{l}2 \\
2\end{array}$ & $\mathrm{E}$ \\
\hline Araliaceae & Schefflera arboricola (Hayata) Merr. & $\begin{array}{l}2 \\
1\end{array}$ & $\mathrm{E}$ \\
\hline \multirow[t]{2}{*}{ Arecaceae } & Dypsis lutescens (H. Wendl.) Beentje \& J. Dransf. & $\begin{array}{c}1 \\
30\end{array}$ & $\mathrm{E}$ \\
\hline & Handroanthus albus (Cham.) Mattos & 21 & $\mathrm{~N}$ \\
\hline \multirow[t]{2}{*}{ Bignoniaceae } & Handroanthus impetiginosus (Mart. ex DC.) Mattos & $\begin{array}{l}21 \\
12\end{array}$ & $\mathrm{~N}$ \\
\hline & Spathodea campanulata Beauv. & $\begin{array}{c}12 \\
3\end{array}$ & $\mathrm{E}$ \\
\hline Caricaceae & Carica papaya $\mathrm{L}$. & $\begin{array}{c}3 \\
54\end{array}$ & $\mathrm{~N}$ \\
\hline Chrysobalanaceae & Licania tomentosa (Benth.) Fritsch & $\begin{array}{c}54 \\
268\end{array}$ & $\mathrm{~N}$ \\
\hline Combretaceae & Terminalia catappa $\mathrm{L}$. & 29 & $\mathrm{E}$ \\
\hline Cupressaceae & Cupressus lusitanica Miller & 5 & $\mathrm{E}$ \\
\hline Cycadaceae & Cycas revoluta Thunb. & 15 & $\mathrm{E}$ \\
\hline \multirow[t]{5}{*}{ Euphorbiaceae } & Euphorbia pulcherrima Willdex Koltz & $\begin{array}{c}15 \\
5\end{array}$ & $\mathrm{E}$ \\
\hline & Bauhinia forficata Link & $\begin{array}{c}5 \\
18\end{array}$ & $\mathrm{~N}$ \\
\hline & Caesalpinia pulcherrima (L.) Sw. & $\begin{array}{c}18 \\
5\end{array}$ & $\mathrm{E}$ \\
\hline & Cajanus cajan (L.) Millsp. & $\begin{array}{l}5 \\
1\end{array}$ & $\mathrm{E}$ \\
\hline & Cassia fistula $\mathrm{L}$. & 1 & $\mathrm{E}$ \\
\hline \multirow{6}{*}{ Fabaceae } & Crotalaria juncea $\mathrm{L}$. & $\begin{array}{l}1 \\
86\end{array}$ & $\mathrm{E}$ \\
\hline & Delonix regia (Bojerex Hook) Raf. & $\begin{array}{c}00 \\
3\end{array}$ & $\mathrm{E}$ \\
\hline & Erythrina indica Lam. & $\begin{array}{c}3 \\
12\end{array}$ & $\mathrm{E}$ \\
\hline & Leucaena leucocephala (Lam.) R. de Wit. & $\begin{array}{l}12 \\
10\end{array}$ & $\mathrm{E}$ \\
\hline & Poincianella pluviosa var. peltophoroides (Benth) L.P. Queiroz & $\begin{array}{c}10 \\
124\end{array}$ & $\mathrm{~N}$ \\
\hline & Tamarindus indica $\mathrm{L}$. & $\begin{array}{c}124 \\
1\end{array}$ & $\mathrm{E}$ \\
\hline Lythraceae & Lagerstroemia indica (L.) Pers. & $\begin{array}{l}1 \\
2\end{array}$ & $\mathrm{E}$ \\
\hline Magnoliaceae & Michelia champaca $\mathrm{L}$. & $\begin{array}{l}2 \\
8\end{array}$ & $\mathrm{E}$ \\
\hline Malpighiaceae & Malpighia glabra L. & $\begin{array}{l}8 \\
5\end{array}$ & $\mathrm{E}$ \\
\hline \multirow{2}{*}{ Malvaceae } & Hibiscus rosa sinensis $L$. & $\begin{array}{c}5 \\
15\end{array}$ & $\mathrm{E}$ \\
\hline & Pachira aquática Aublet & 227 & $\mathrm{~N}$ \\
\hline Melastomataceae & Tibouchina granulosa (Ders.) Cogn. & 197 & $\mathrm{~N}$ \\
\hline \multirow[t]{2}{*}{ Meliaceae } & Melia azedarach L. & $\begin{array}{c}191 \\
8\end{array}$ & $\mathrm{E}$ \\
\hline & Artocarpus integrifolia $\mathrm{L}$. & 2 & $\mathrm{E}$ \\
\hline \multirow[t]{3}{*}{ Moraceae } & Ficus benjamina $\mathrm{L}$. & $\begin{array}{c}2 \\
503\end{array}$ & $\mathrm{E}$ \\
\hline & Morus nigra L. & 4 & $\mathrm{E}$ \\
\hline & Callistemon viminallis (Sol.) Ex Gaertn & $\begin{array}{l}4 \\
5\end{array}$ & $\mathrm{E}$ \\
\hline \multirow[t]{2}{*}{ Myrtaceae } & Eugenia uniflora L. & 1 & $\mathrm{~N}$ \\
\hline & Psidium guajava $\mathrm{L}$. & $\begin{array}{l}1 \\
17\end{array}$ & $\mathrm{~N}$ \\
\hline Oleaceae & Ligustrum lucidum W. T. Aiton & 26 & $\mathrm{E}$ \\
\hline Papaveraceae & Chelidonium majus L. & 1 & $\mathrm{E}$ \\
\hline Proteaceae & Grevillea robusta A. Cunn. & 2 & $\mathrm{~N}$ \\
\hline Punicaceae & Punica granatum L. & 1 & $\mathrm{E}$ \\
\hline Rosaceae & Eriobotrya japonica (Thunb.) Lindl. & $\begin{array}{l}1 \\
5\end{array}$ & $\mathrm{E}$ \\
\hline Rubiaceae & Coffea arabica $\mathrm{L}$. & $\begin{array}{l}3 \\
2\end{array}$ & $\mathrm{E}$ \\
\hline \multirow{2}{*}{ Rutaceae } & Citrus limonia (L.) Osbeck & 30 & $\mathrm{E}$ \\
\hline & Murraya paniculata (L.) Jack. & 25 & $\mathrm{E}$ \\
\hline \multirow[t]{2}{*}{ Verbenaceae } & Duranta repens Aurea L. & $\begin{array}{l}25 \\
11\end{array}$ & $\mathrm{~N}$ \\
\hline & TOTAL & 1.885 & \\
\hline
\end{tabular}

Em que: IND = quantidade de indivíduos encontrados; $\mathrm{P}=$ procedência dos indivíduos arbóreos; $\mathrm{N}=$ indivíduos nativos; $\mathrm{E}=$ indivíduos denominados exóticos. 


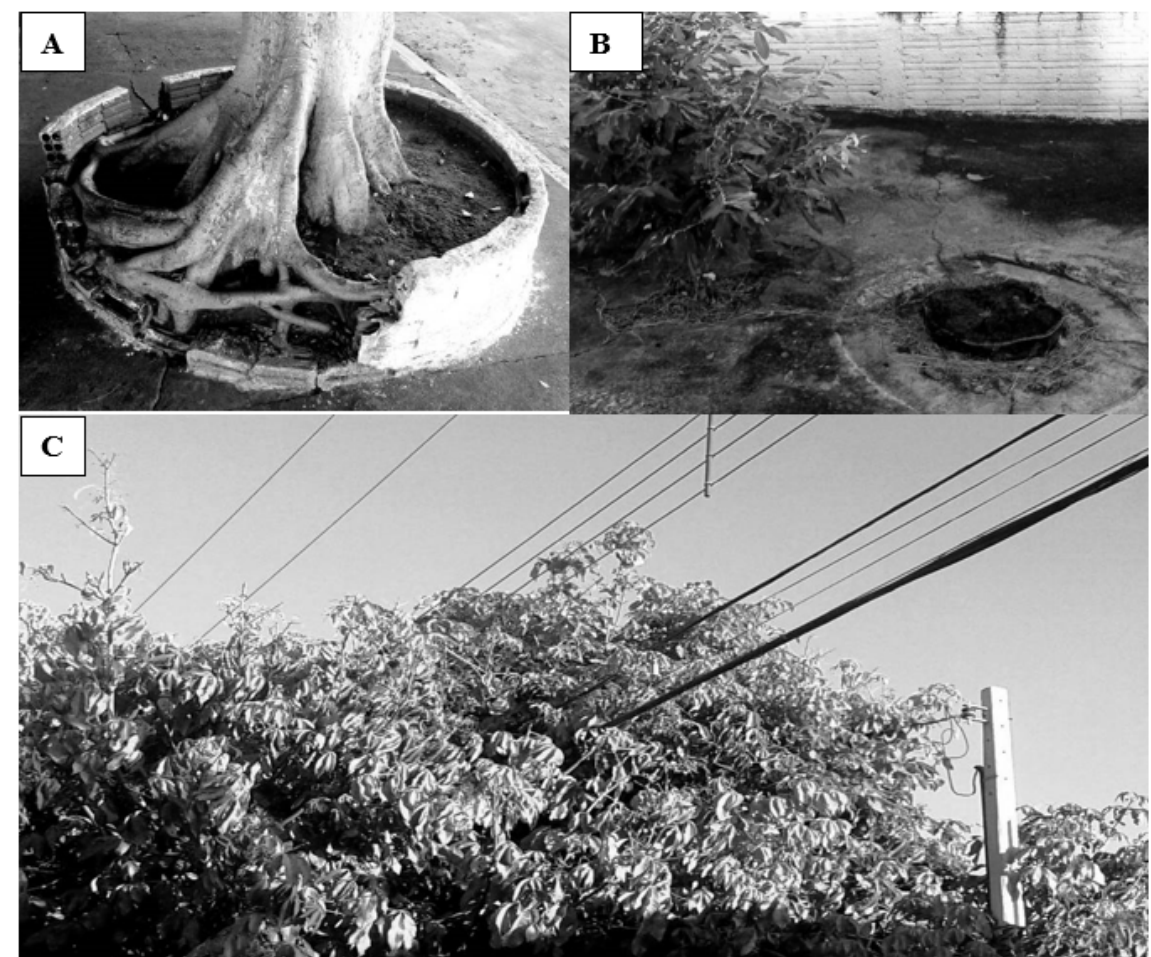

FIGURA 2: Interferências da arborização no meio urbano. (A) Rompimento de calçadas provocado por Ficus benjamina L. (B) Toco presente em local destinado ao passeio. (C) Galhos de Pachira aquatica Aublet em conflito com a fiação.

FIGURE 2: Interference of afforestation in urban areas. (A) Breaking sidewalks caused by Ficus benjamina L. (B) Stump this in place for the ride. (C) Pachira Aquatica Aublet branches in conflict with the wiring.

ambientais pela rede estadual de ensino. De acordo com a Prefeitura Municipal, a primeira turma de técnicos na área deverá se formar ainda este ano e auxiliará no desenvolvimento de questões correlatas ao estudo.

Em análise às condições atuais da arborização e aos dados obtidos com a realização das entrevistas, notou-se que Cafeara utiliza parcialmente a arborização como forma sustentável, tendo em destaque: maior incidência de indivíduos nativos, controle regular da poda, realização recente de inventário arbóreo, além do desenvolvimento de projetos voltados para a sustentabilidade. Em contrapartida, verifica-se que para potencializar o uso da arborização existente é necessário ainda o aprimoramento de algumas ideias, tendo como referenciais sistemas práticos adotados em outras municipalidades.

Em Campo Mourão - PR, por exemplo, a gestão pública municipal utiliza resíduos da poda como adubo para os próprios canteiros centrais. Apesar de ser uma iniciativa recente, esta técnica já produz resultados, reduzindo custos com adubação e atribuindo destinação correta aos resíduos gerados durante o processo de poda.

Na cidade de Brasília - DF, a arborização é empregada como benefício social para comunidade, sendo utilizadas espécies arbóreas frutíferas em locais como praças e canteiros. De acordo com Machado, Alencar e Rodrigues (1992), essas espécies servem como alimento para os moradores locais e estimulam a visitação às praças durante o período de frutificação. No entanto, cumpre-se ressaltar que Costa et al. (1996) salientam a existência de alguns problemas associados a árvores frutíferas, como a suscetibilidade a pragas e os riscos de contaminantes presentes nos frutos.

Outra solução também recomendada para o município é a utilização de espécies arbóreas dispostas em locais com forte insolação no período da tarde, com o propósito de melhoria do microclima local. Espécies de porte arbóreo auxiliam na atenuação da temperatura e podem reduzir o consumo de energia 


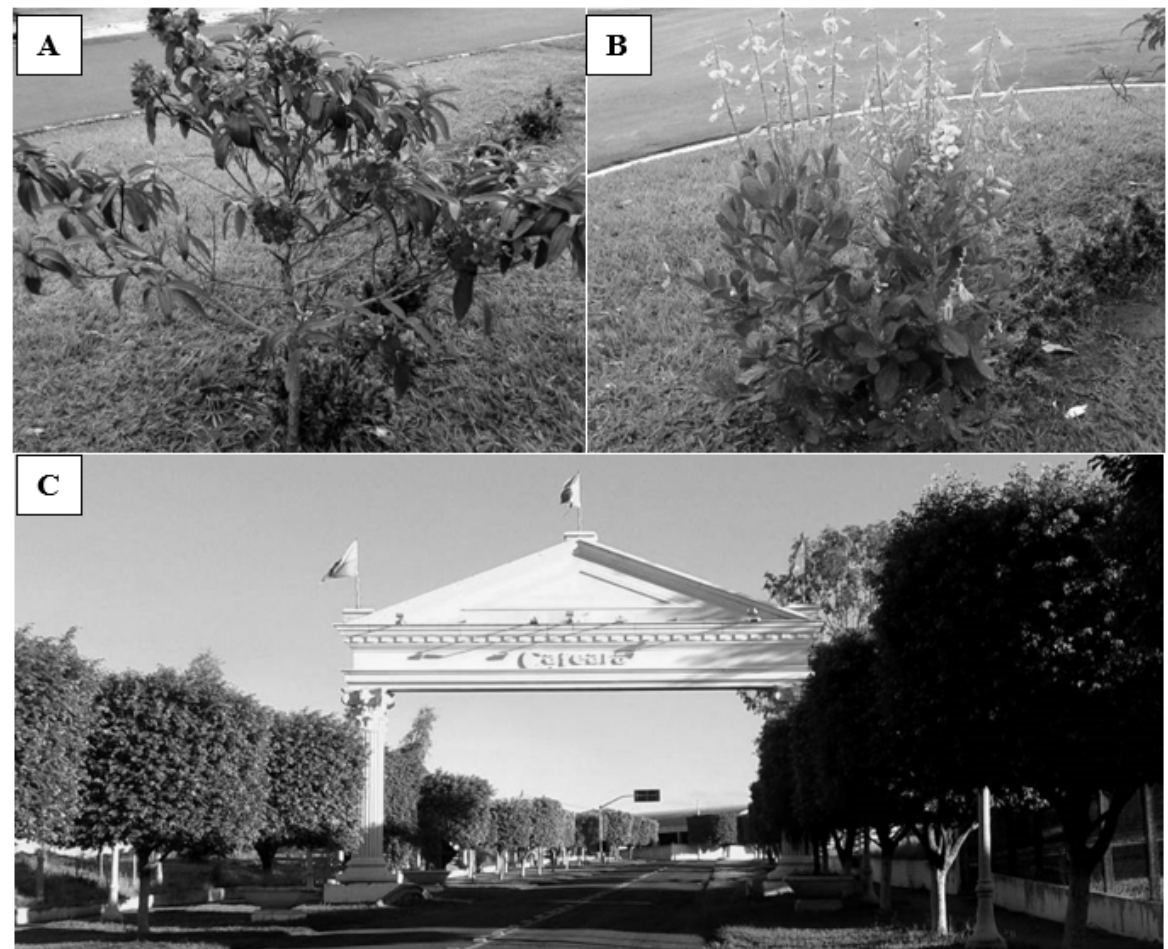

FIGURA 3: Uso sustentável da arborização. (A) Muda em campo da espécie nativa Tibouchina granulosa (Ders.) Cogn. (B) Espécimes de Crotalaria juncea L. cultivados para auxílio no combate à dengue. (C) Espécimes de Ficus benjamina L. com aplicação de poda às margens da PR 543.

FIGURE 3: Sustainable use of afforestation. (A) Seedlings in the field of native species Tibouchina granulosa (Ders.) Cogn. (B) Specimens of Crotalaria juncea L. grown to aid in the fight against dengue. (C) Specimens of Ficus benjamina L. with application of pruning on the shores of PR 543 road.

elétrica vinculado ao uso de ventiladores e ar condicionados.

Outro fator associado ao uso sustentável da arborização fundamenta-se no emprego de espécies com potencial florístico, propiciando beleza natural e bem-estar à população. Algumas espécies como Handroanthus impetiginosus (Mart. ex DC.) Mattos e Hibiscus rosa sinensis L. apresentam floração aparente e de grande destaque na paisagem urbana. Estes indivíduos além de atrair animais de pequeno porte, aprimoram aspectos visuais e possibilitam maior interação homem-natureza.

$\mathrm{Na}$ realidade, todos os questionamentos e sugestões aplicados podem ser atribuídos pela determinação de um simples plano de manejo bem estruturado, fundamentado com base no diagnóstico arbóreo realizado no município.

\section{CONCLUSÕES}

Por todo exposto, verificou-se que a cidade de Cafeara - PR tem desenvolvido projetos com o intuito de melhoria das condições arbóreas existentes. Constatou-se que a atual gestão municipal trabalha com o emprego de mudas nativas, utilização de espécies para controle da dengue e formação de profissionais habilitados na área.

Apesar de os conceitos desenvolvidos, com aprimoramento em questões sociais e ambientais, ainda há necessidade de avanços principalmente de ordem econômica, a fim de evitar custos extras voltados à manutenção da poda e reconstrução de calçamentos danificados.

Como forma de amenizar os problemas existentes recomenda-se para o gestor municipal o uso 
de técnicas aplicáveis em outras localidades como: emprego de espécies com potencial florístico e/ou frutívoro, utilização de resíduos da poda em benefício da própria arborização, plantio de espécies com porte compatível às dimensões existentes no local, além do manejo estruturado na elaboração de um plano de arborização.

\section{AGRADECIMENTOS}

Agradeço a Coordenação de Aperfeiçoamento de Pessoal de Nível Superior (CAPES) pela concessão da bolsa de estudo.

\section{REFERÊNCIAS}

ANGIOSPERM PHYLOGENY GROUP III. An update of the Angiosperm Phylogeny Group classification for the orders and families of flowering plants: APG III. Botanical Journal of the Linnean Society, London, v. 16, p. 105-121, 2009.

BALENSIEFER, M.; WIECHETECK, M. Arborização de cidades. 1. ed. Curitiba: Instituo de Terras e Cartografia, 1985.

BIONDI, D.; ALTHAUS, M. Árvores de rua de Curitiba: cultivo e manejo. 1. ed. Curitiba: FUPEF, 2005. CERQUEIRA, M. C. R.; SILVA, D. A. M. Análise do processo de arborização pública da cidade de Santanópolis - Bahia. [s. 1.]: Inter - saberes, 2013.

COSTA, L. M. S. A. et al. Arborização das ruas do bairro de Copacabana. In: CONGRESSO BRASILEIRO SOBRE ARBORIZAÇÃO URBANA, 3., Salvador. Anais... Salvador: SBAU, 1996.

DANTAS, I. C.; SOUZA, C. M. C. Arborização urbana na cidade de Campina Grande - PB: Inventário e suas espécies. Revista de Biologia e Ciência da Terra, Campina Grande, v. 4, n. 2, jul. 2004.

ELETRICIDADE DE SÃO PAULO. Guia de Planejamento e Manejo da Arborização Urbana. São Paulo: Gráfica Cesp, 1995.

FIDALGO, O.; BONONI, V. L. R. Técnicas de coleta, preservação e herborização de material botânico. São Paulo: Instituto de Botânica, 1989.

GOUVÊA, I. Cobertura Vegetal Urbana. Revista Assentamentos Humanos, Marília, v. 3, n. 1, p. 17-24, out. 2001.

INTERNATIONAL PLANT NAMES INDEX. The International Plant Name Index, 2013. Disponível em: $<$ http://www.ipni.org/>. Acesso em: 25 out. 2014.

INSTITUTO DE TERRAS, CARTOGRAFIA E GEOCIÊNCIAS. Dados Geoespaciais de referência. 2014. Disponível em: <http://www.itcg.pr.gov.br/modules/faq/category.php?categoryid=8\#>. Acesso em: 7 nov. 2014.

JARDIM BOTÂNICO DO RIO DE JANEIRO. Lista de espécies da flora do Brasil. 2013. Disponível em: $<$ http://floradobrasil.jbrj.gov.br/>. Acesso em: 15 dez. 2014.

LAERA, L. H. N. Arborização Urbana e o sequestro de carbono: um potencial mercado a ser explorado na cidade do Rio de Janeiro. In: ENCONTRO ECO - DESENVOLVIMENTO URBANO E MEIO AMBIENTE, 6., Brasília, 2005. Anais... Brasília, 2005. p. 1-21.

MACHADO, J. W. B.; ALENCAR, F. O. C. C.; RODRIGUES, M. G. Árvores de Brasília. 1. ed. Brasília: Secretaria de Obras e Serviços Públicos, Departamento de Parques e Jardins, 1992. 100 p.

MELLO FILHO, L. E. Arborização Urbana. In: ENCONTRO NACIONAL SOBRE ARBORIZAÇÃO URBANA, 10., 1985, Porto Alegre. Anais... Porto Alegre: Prefeitura Municipal de Porto Alegre, Secretaria Municipal do Meio Ambiente, 1985. p. 117-127.

MILANO, M. S. Avaliação quali-quantitativa e manejo da arborização urbana: exemplo de Maringá - PR. 1988. 120 f. Tese (Doutorado em Ciências Florestais) - Ciências Agrárias. Universidade Federal de Curitiba, Curitiba, 1988.

MILANO, M.; DALCIN, E. Arborização de vias públicas. 1. ed. Rio de Janeiro: Light, 2000.

PELEGRIM, E. A. P.; LIMA, A. P. L.; LIMA, S. F. Avaliação qualitativa e quantitativa da arborização no bairro Flamboyant em Chapadão do Sul, MS. Revista Sociedade Brasileira de Arborização Urbana, Piracicaba, v. 7, n. 1, p. 126-142, mar. 2012. 